Hydrol. Earth Syst. Sci., 17, 3355-3369, 2013

www.hydrol-earth-syst-sci.net/17/3355/2013/

doi:10.5194/hess-17-3355-2013

(C) Author(s) 2013. CC Attribution 3.0 License.

\title{
Improving simulation of soil moisture in China using a multiple meteorological forcing ensemble approach
}

\author{
J.-G. Liu ${ }^{1,2}$ and Z.-H. Xie ${ }^{1}$ \\ ${ }^{1}$ State Key Laboratory of Numerical Modeling for Atmospheric Sciences and Geophysical Fluid Dynamics (LASG), \\ Institute of Atmospheric Physics, Chinese Academy of Sciences, Beijing, 100029, China \\ ${ }^{2}$ University of Chinese Academy of Sciences, Beijing, 100049, China
}

Correspondence to: Z.-H. Xie (zxie@lasg.iap.ac.cn)

Received: 3 March 2013 - Published in Hydrol. Earth Syst. Sci. Discuss.: 15 March 2013

Revised: 9 July 2013 - Accepted: 19 July 2013 - Published: 3 September 2013

\begin{abstract}
The quality of soil-moisture simulation using land surface models depends largely on the accuracy of the meteorological forcing data. We investigated how to reduce the uncertainty arising from meteorological forcings in a simulation by adopting a multiple meteorological forcing ensemble approach. Simulations by the Community Land Model version 3.5 (CLM3.5) over mainland China were conducted using four different meteorological forcings, and the four sets of soil-moisture data related to the simulations were then merged using simple arithmetical averaging and Bayesian model averaging (BMA) ensemble approaches. BMA is a statistical post-processing procedure for producing calibrated and sharp predictive probability density functions (PDFs), which is a weighted average of PDFs centered on the biascorrected forecasts from a set of individual ensemble members based on their probabilistic likelihood measures. Compared to in situ observations, the four simulations captured the spatial and seasonal variations of soil moisture in most cases with some mean bias. They performed differently when simulating the seasonal phases in the annual cycle, the interannual variation and the magnitude of observed soil moisture over different subregions of mainland China, but no individual meteorological forcing performed best for all subregions. The simple arithmetical average ensemble product outperformed most, but not all, individual members over most of the subregions. The BMA ensemble product performed better than simple arithmetical averaging, and performed best for all fields over most of the subregions. The BMA ensemble approach applied to the ensemble simulation reproduced anomalies and seasonal variations in observed soil-moisture
\end{abstract}

values, and simulated the mean soil moisture. It is presented here as a promising way for reproducing long-term, highresolution spatial and temporal soil-moisture data.

\section{Introduction}

Soil moisture plays a very important role in the global hydrological cycle and energy balance within the land-atmosphere interaction in the climate system (Robock et al., 1998). It is also a crucial variable for monitoring land surface conditions that force extreme events such as drought and flood (Wang et al., 2009, 2011; Albergel et al., 2012). As a consequence, it is very important to obtain accurate high-resolution spatial and temporal soil-moisture information. Currently, land surface models (LSMs) have been widely used to provide estimates of soil moisture on global or continental scales; however, LSM simulations of soil moisture still contain large errors. One of the main sources of error is the uncertainty in the meteorological forcing. The accuracy of a simulation by LSM depends largely on the quality of its meteorological forcing, and is especially sensitive to precipitation, radiation and temperature (Wei et al., 2008; Li and Ma, 2010; Wang and Zeng, 2011)

Meteorological forcing driving a land surface model is generally produced by combining in situ observations, remote sensing measurements and reanalysis data (Qian et al., 2006; Sheffield et al., 2006). It has been found that simulations by CLM3.5 are improved using a meteorological forcing obtained through merging many more in situ observations 
of precipitation and temperature (Wang and Zeng, 2011). At a regional scale, many more in situ observations and remote sensing measurements are available for LSM use. For example, high-resolution space/time meteorological forcings for mainland China have been developed by $\mathrm{He}$ (2010), Shi (2008), Shi et al. (2011) and Tian et al. (2010), but various errors are still found in soil-moisture simulations by LSM using different forcings. It has been found that the simplest ensemble approach (simple arithmetical averaging of soil moisture from an individual ensemble member) is an effective strategy for improving the simulation of soil moisture, but it is still not superior to the best individual ensemble member in most cases (Guo et al., 2007). Bayesian model averaging (BMA) was proposed by Raftery et al. (2005) as an ensemble post-processing approach for calibrating forecast ensembles from numerical weather models and producing calibrated and sharply predictive probability density functions (PDFs). Many previous studies, which applied the BMA approach to a range of different weather and seasonal climate ensemble forecasts, have demonstrated that it is superior to the simple arithmetical averaging method and provides a quantitative description of total predictive uncertainty through the PDF (Raftery et al., 2005; Duan et al., 2007; Vrugt et al., 2008; Liu et al., 2013).

In the present work, four meteorological forcings were used to conduct simulations over mainland China using Community Land Model version 3.5 (CLM3.5, Oleson et al., 2007, 2008). Then the four sets of simulated soil-moisture data were merged using a BMA ensemble approach to reduce the CLM3.5 simulation uncertainty arising from the four meteorological forcings, and improve soil-moisture simulation.

This paper is organized as follows. We briefly describe the LSM CLM3.5, four various meteorological forcings and in situ observation of soil moisture in China in Sect. 2. Section 3 briefly describes the experiment design and ensemble approach. Validation and comparison of individual member and ensemble simulations of soil moisture in eight climatic subregions of mainland China are presented in Sect. 4. We discuss the results in Sect. 5 and finally give a summary and conclusions in Sect. 6.

\section{Model and data}

\subsection{Land surface model CLM3.5}

The LSM used in this study was CLM3.5 (Oleson et al., 2007) released by the National Center for Atmospheric Research (NCAR). This model is a modified version of CLM3.0 (Oleson et al., 2004), and has significantly improved the simulation of many variables in the hydrological cycle and the spatial distribution of vegetation. A new surface dataset was introduced to improve land surface representation and improve the simulation of surface albedo, near-surface temperature and precipitation (Lawrence and Chase, 2007). With respect to hydrological process, the modifications to CLM3.5 mainly include canopy interception, surface and subsurface runoff, water table depth, frozen soil, soil water availability and soil evaporation.

For the hydrological process, CLM3.5 simulates changes in canopy water $\Delta W_{\text {can }}$, snow water $\Delta W_{\text {sno, }}$, soil water $\Delta w_{\text {liq }, i}$, soil ice $\Delta w_{\text {ice, } i}$, and water in the unconfined aquifer $\Delta W_{\mathrm{a}}$ by parameterizing interception, throughfall, canopy drip, snow accumulation and melt, water transfer between snow layers, infiltration, surface runoff, sub-surface drainage, redistribution within the soil column, and groundwater discharge and recharge. The total water balance equation is

$$
\begin{aligned}
& \Delta W_{\text {can }}+\Delta W_{\text {sno }}+\sum_{i=1}^{N}\left(\Delta w_{\text {liq }, i}+\Delta w_{\text {ice }, i}\right)+\Delta W_{\mathrm{a}} \\
& =\left(q_{\text {rain }}+q_{\text {sno }}-E_{\mathrm{v}}-E_{\mathrm{g}}-q_{\text {over }}-q_{\text {drai }}-q_{\text {rgwl }}\right) \Delta t,
\end{aligned}
$$

where $q_{\mathrm{rain}}$ is rainfall, $q_{\mathrm{sno}}$ is snowfall, $E_{\mathrm{v}}$ is evapotranspiration from vegetation, $E_{\mathrm{g}}$ is ground evaporation, $q_{\text {over }}$ is surface runoff, $q_{\text {drai }}$ is sub-surface drainage, $q_{\mathrm{rgwl}}$ is runoff from glaciers, wetlands and lakes, and runoff from other surface types due to snow capping, $N$ is the number of soil layers, and $\Delta t$ is the time step. The total $0-3.43 \mathrm{~m}$ soil column is divided into 10 layers of variable thickness from $0.0175 \mathrm{~m}$ to $1.1370 \mathrm{~m}$. The node depth $d_{i}$, thicknesses $\Delta d_{i}$, and interface depth $d_{h, i}$ of the $i$ th soil layer are given by

$$
\begin{aligned}
d_{i} & =\frac{\exp \left(\frac{i-0.5}{2}\right)-1}{40}, \quad i=1,2, \cdots, 10, \\
\Delta d_{i} & = \begin{cases}\left(d_{1}+d_{2}\right) / 2, & i=1, \\
\left(d_{i+1}-d_{i-1}\right) / 2, & i=2,3, \cdots, 9, \\
d_{i}-d_{i-1}, & i=10,\end{cases} \\
d_{h, i} & = \begin{cases}\left(d_{i}+d_{i+1}\right) / 2, & i=1,2, \cdots, 9, \\
d_{i}+0.5 \Delta d_{i}, & i=10 .\end{cases}
\end{aligned}
$$

Figure 1 shows the hydrological process simulated by CLM3.5 (right) and the soil-moisture layer formation adopted in the CLM3.5 simulation (left).

A detailed description of the physical processes, modification and performance of CLM3.5 was given in Oleson et al. (2004, 2008) and Lawrence et al. (2007).

\subsection{In situ observations of soil moisture}

The observed soil-moisture data were obtained from the China Meteorological Administration (CMA) National Meteorological Information Center (NMIC). The original data for 1992-2011 from 778 stations had been collected from agricultural meteorological stations located in farmland across mainland China. The soil moisture was measured three times on the 8th, 18th and 28th day of every month in the warm season at soil depths of $10 \mathrm{~cm}, 20 \mathrm{~cm}, 50 \mathrm{~cm}, 70 \mathrm{~cm}$ and $100 \mathrm{~cm}$. No measurements were recorded in frozen soil. Soil-moisture content was measured by weight difference, and recorded originally as mass percentage $\theta_{\mathrm{m}}$, i.e., 
Three soil layers, $i-1, i$, and $i+1$

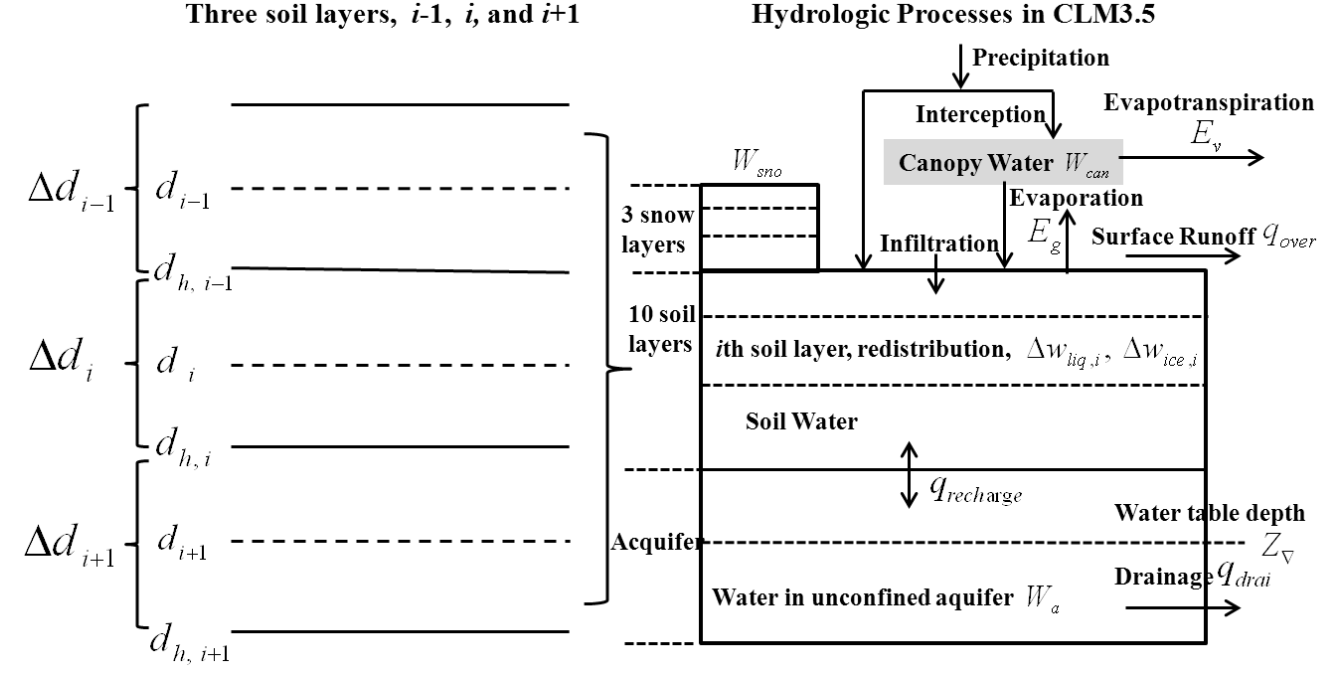

Fig. 1. Hydrological process simulated by CLM3.5 (right) and soil-moisture layer formation in CLM3.5 (left).

$\theta_{\mathrm{m}}=\frac{m_{\mathrm{w}}}{m_{\mathrm{s}}}$,

where $m_{\mathrm{w}}$ is the weight of soil water, and $m_{\mathrm{s}}$ is the weight of dried soil. The original data were obtained from agricultural meteorology stations which serve for agriculture, and were expressed as relative soil-moisture content $S_{\mathrm{m}}$ in the soil-moisture dataset as follows:

$S_{\mathrm{m}}=\frac{\theta_{\mathrm{m}}}{\theta}$,

where $\theta$ is the volumetric soil-moisture content at field capacity. The dataset included the information for every station. The relative soil-moisture content was then converted to volumetric soil moisture, with units $\mathrm{m}^{3} \mathrm{~m}^{-3}$ :

$\theta_{\mathrm{v}}=S_{\mathrm{m}} \times \frac{\rho_{\mathrm{s}}}{\rho_{\mathrm{w}}} \times \theta$.

Similarly, the mass percentage was also converted to volumetric soil moisture:

$\theta_{\mathrm{v}}=\theta_{\mathrm{m}} \times \frac{\rho_{\mathrm{s}}}{\rho_{\mathrm{w}}}$,

where $\rho_{\mathrm{S}}$ and $\rho_{\mathrm{w}}$ are the bulk densities of soil and water, respectively. This soil-moisture observation dataset has been widely used to study the variations of soil moisture and for evaluating the LSM-simulated soil moisture in China (Liu et al., 2001; Li et al., 2004; Zhang, 2009; Wang and Zeng, 2011), and is constantly updated. In this study, a simple quality control procedure was performed on the updated soil-moisture observations in terms of observation frequency (i.e., the ratio between the available measurement times and the period from March to September) (Zhang, 2009). The monthly soil-moisture content values at depths of $0-10 \mathrm{~cm}$, $10-20 \mathrm{~cm}$ and $70-100 \mathrm{~cm}$ at 411 stations from July 2005 to June 2010 were then compared with the simulated values at those depths. The 411 stations were grouped into eight subregions on the basis of the spatial patterns of the centers of dryness and wetness throughout China, based on Zhu (2003); these are defined in Table 1. Figure 2 shows the eight subregions and the location of all 411 stations, 391 of which were located in the eight subregions in this study.

\subsection{Multiple meteorological forcings}

An offline CLM3.5 simulation requires external meteorological forcing data that includes air temperature, wind speed, specific humidity, surface pressure, precipitation and radiation. In this study, four sets of meteorological forcing over mainland China developed by different institutions were used in our multiple forcings ensemble system. They include

- Forcing data for China (hereafter FY) developed by Shi (2008) and Shi et al. (2011), which introduced inverted precipitation and ground-incident solar radiation products acquired through the high-resolution spatial and temporal FY2C geostationary satellite data for precipitation and solar radiation. The original inverted precipitation products from the China Satellite Data Service Center (http://satellite.cma.gov.cn) are estimated 6-hourly accumulated precipitation output. Shi (2008) used an inversion algorithm to convert these data to hourly accumulated precipitation at a spatial resolution of $0.1^{\circ}$ using a time-weighted interpolation method based on hourly geostationary satellite cloud category information. The temporal resolution of original inverted ground-incident solar radiation products is 1 day; the spatial resolution is $0.5^{\circ}$. In addition, the 


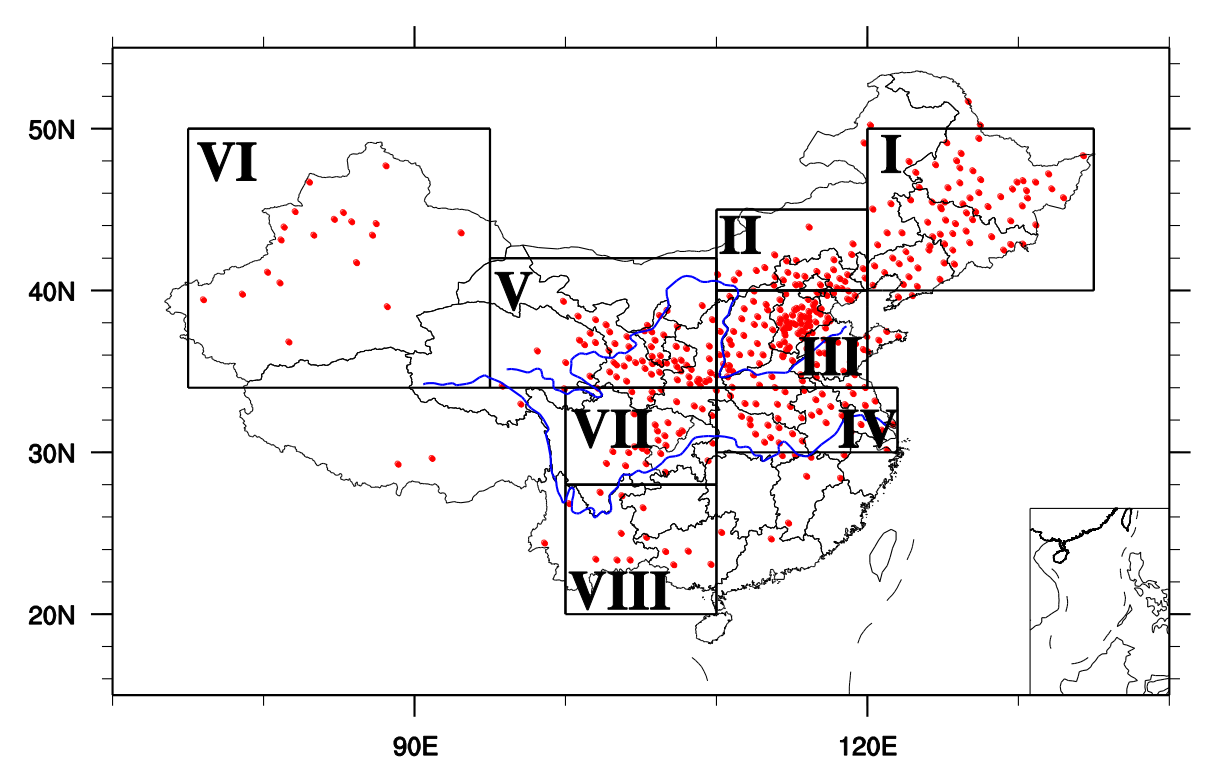

Fig. 2. Locations of the 411 in situ soil-moisture observation stations (red dots). Also shown (boxes) are the eight subdivisions defined in Table 1 for regional averaging.

Table 1. Locations of the eight subregions in China.

\begin{tabular}{lllr}
\hline Identification & Region name & Location & $\begin{array}{r}\text { Number of } \\
\text { observational } \\
\text { stations }\end{array}$ \\
\hline China I & northeast China & $120^{\circ} \mathrm{E}-135^{\circ} \mathrm{E}$, & 74 \\
China II & northern North China & $40^{\circ} \mathrm{N}-50^{\circ} \mathrm{N}$ & $110^{\circ} \mathrm{E}-120^{\circ} \mathrm{E}$, \\
& & $40^{\circ} \mathrm{N}-45^{\circ} \mathrm{N}$ & 34 \\
China III & southern North China & $110^{\circ} \mathrm{E}-120^{\circ} \mathrm{E}$, & 116 \\
& & $34^{\circ} \mathrm{N}-40^{\circ} \mathrm{N}$ & \\
China IV & middle and lower Yangtze River basin & $110^{\circ} \mathrm{E}-122^{\circ} \mathrm{E}$, & 36 \\
& & $30^{\circ} \mathrm{N}-34^{\circ} \mathrm{N}$ \\
China V & eastern northwest China & $95^{\circ} \mathrm{E}-110^{\circ} \mathrm{E}$, & $34^{\circ} \mathrm{N}-42^{\circ} \mathrm{N}$ \\
China VI & western northwest China & $80^{\circ} \mathrm{E}-95^{\circ} \mathrm{E}$, & 67 \\
& & $34^{\circ} \mathrm{N}-50^{\circ} \mathrm{N}$ & $190^{\circ} \mathrm{E}-110^{\circ} \mathrm{E}$, \\
China VII & northern southwest China & $28^{\circ} \mathrm{N}-34^{\circ} \mathrm{N}$ & 32 \\
& & $100^{\circ} \mathrm{E}-110^{\circ} \mathrm{E}$, & 13 \\
China VIII & southern southwest China & $20^{\circ} \mathrm{N}-28^{\circ} \mathrm{N}$ & \\
& & & \\
\hline
\end{tabular}

near-surface air temperature, pressure, wind speed and humidity were derived from National Centers for Environmental Prediction (NCEP)/NCAR reanalysis data. Shi et al. (2011) and Jia et al. (2013) used this information as the external meteorological forcing of land data assimilation system.

- Forcing data for China (hereafter ITP) established by $\mathrm{He}$ (2010), which merged the observations from 740 operational stations of the CMA with the corresponding Princeton global meteorological forcing dataset (Sheffield et al., 2006) to produce near-surface air temperature, pressure, wind speed and specific humidity fields. This combined three precipitation datasets to determine the precipitation field, and corrected the Global Energy and Water Cycle Experiment-Surface Radiation Budget (GEWEX-SRB) (Pinker and Laszlo, 1992) shortwave radiation dataset with reference to radiation estimates (Yang et al., 2006) in order to ascertain the incident shortwave radiation fields. Chen et 
Table 2. Comparison of major features of four sets of meteorological forcing data.

\begin{tabular}{|c|c|c|c|c|c|}
\hline Forcing & Resolution & Coverage & Composition & Institution & Reference \\
\hline FY & $1 \mathrm{~h} 0.2^{\circ} \times 0.2^{\circ}$ & $\begin{array}{l}15^{\circ} \mathrm{N}-55^{\circ} \mathrm{N} \\
75^{\circ} \mathrm{E}-135^{\circ} \mathrm{E} \\
2005.7-2010.6\end{array}$ & $\begin{array}{l}\text { (1) precipitation and ground- incident solar ra- } \\
\text { diation from FY2C satellite data; } \\
\text { (2) NCEP/NCAR reanalysis data }\end{array}$ & CMA & $\begin{array}{l}\text { Shi (2008); } \\
\text { Shi et al. (2011) }\end{array}$ \\
\hline ITP & $3 \mathrm{~h} 0.1^{\circ} \times 0.1^{\circ}$ & $\begin{array}{l}15^{\circ} \mathrm{N}-55^{\circ} \mathrm{N} \\
70^{\circ} \mathrm{E}-140^{\circ} \mathrm{E} \\
1979-2011\end{array}$ & $\begin{array}{l}\text { (1) near-surface air temperature, pressure, wind } \\
\text { speed, specific, humidity and precipitation from } \\
740 \text { operational stations of the CMA; } \\
\text { (2) Princeton meteorological forcing data; } \\
\text { (3) TRMM3B42 and APHRODITE } \\
\text { precipitation product; } \\
\text { (4) GEWEX-SRB shortwave radiation data and } \\
\text { radiation estimates from a hybrid radiation } \\
\text { model }\end{array}$ & ITPCAS & $\begin{array}{l}\text { He (2010); Chen et al. (2011); } \\
\text { Sheffield et al. (2006); Yang et } \\
\text { al. (2006); Yatagai et al. (2009); } \\
\text { Huffman et al. (2007); } \\
\text { Pinker and Laszlo (1992) }\end{array}$ \\
\hline TIAN & $6 \mathrm{~h} 1.875^{\circ} \times 1.915^{\circ}$ & $\begin{array}{l}15^{\circ} \mathrm{N}-55^{\circ} \mathrm{N} \\
70^{\circ} \mathrm{E}-140^{\circ} \mathrm{E} \\
2004-2010\end{array}$ & $\begin{array}{l}\text { (1) precipitation and temperature from } 740 \mathrm{op}- \\
\text { erational stations of the CMA; } \\
\text { (2) ERA-interim reanalysis data; }\end{array}$ & IAPCAS & Tian et al. (2010) \\
\hline JRA & $6 \mathrm{~h} 1.125^{\circ} \times 1.125^{\circ}$ & $\begin{array}{l}\text { Global } \\
\text { 1979-2011 }\end{array}$ & JRA-25 reanalysis data & JMA & Onogi et al. (2008) \\
\hline
\end{tabular}

* China Meteorological Administration (CMA), Institute of Tibetan Plateau Research, Chinese academy of Sciences (ITPCAS), Institute of Atmospheric Physics, Chinese Academy of Sciences (IAPCAS), Japanese 25 yr Reanalysis (JRA-25), Japan Meteorological Agency (JMA), Tropical Rainfall Measuring Mission (TRMM), Asian Precipitation-Highly Resolution Observational Data Integration Toward Evaluation of Water Resources (APHRODITE), Global Energy and Water Cycler Experiment-Surface Radiation Budget (GEWEX-SRB) precipitation products (Huffman et al., 2007), precipitation data.

al. (2011) demonstrated that simulations driven by ITP forcing improve land surface temperature modeling for dry land in China.

- Forcing data (hereafter TIAN) developed by Tian et al. (2010), which extended the observation-based atmospheric forcing data from Qian et al. (2006) up until 2010, using the ERA-interim data, and temperature and precipitation from 740 operational stations of the CMA. Tian et al. (2010) used these data as the external meteorological forcing of land data assimilation system.

- Japanese 25 yr reanalysis data (JRA-25) (Onogi et al., 2008) (hereafter JRA).

Table 2 summarizes the primary features of and differences between these forcings. Since precipitation is the driving force of soil-moisture variability, and that precipitation uncertainty accounts for about $2 / 3$ of the total soil-moisture uncertainty arising from all forcing data (Wei et al., 2008), we compared the precipitation from the above four forcings. Figure 3 shows the spatial distribution for the fiveyear (July 2005-June 2010) averaged precipitation from the four forcings: in general, the precipitation from each of the forcings displayed a similar spatial pattern, i.e., obvious northwest-northeast and northwest-southeast gradients from dry to wet. However, FY indicates wetter conditions than the other three forcings in most areas of mainland China, and JRA is slightly drier than other three forcings, especially in northern China (China I, II, III).

Figure 4 shows the time series of precipitation from the four forcings for the period July 2005-June 2010 in the eight subregions of mainland China defined in Table 1. Precipitation figures from FY, TIAN, ITP and JRA display a similar temporal variation in most cases. However, FY is wetter than the other three forcings in most subregions, especially for the period January 2010-June 2010, and shows greater temporal variation in most subregions. JRA is slightly drier than other three forcings, and shows smaller temporal variation in most subregions except China VII, but it indicates a higher peak value in the wet season. Here, the area average accounts for only those grid cells nearest the relevant soil-moisture observation stations.

\section{Experiment design and ensemble approach}

\subsection{Experiment design}

The four soil-moisture simulations were determined by the following forcings (described in Table 2), which are coded as (1) CLM3.5_FY (for the FY simulation); (2) CLM3.5_TIAN (for the TIAN simulation); (3) CLM3.5_ITP (for the ITP simulation); (4) CLM3.5 JRA (for the JRA simulation). In order to spin-up for the deep soil layers and achieve an equilibrium state of the CLM3.5, the model first adopted ITP meteorological forcing from 1979 to 2010, and the first files on 1 January 2011 and 1 July 2010 were saved and used to initialize all four simulations at the beginning of each of the four forcings (1 January 1979 for ITP and JRA; 1 January 2004 for TIAN; 1 July 2005 for FY). These were all run at resolutions of $0.1^{\circ}$ latitude $\times 0.1^{\circ}$ longitude in CLM3.5, and the forcing data were also interpolated to $0.1^{\circ}$. The time step is 1800s. Because the different forcings spanned four different time periods, in this study we chose the time span that was common to all four, which was July 2005-June 2010. 

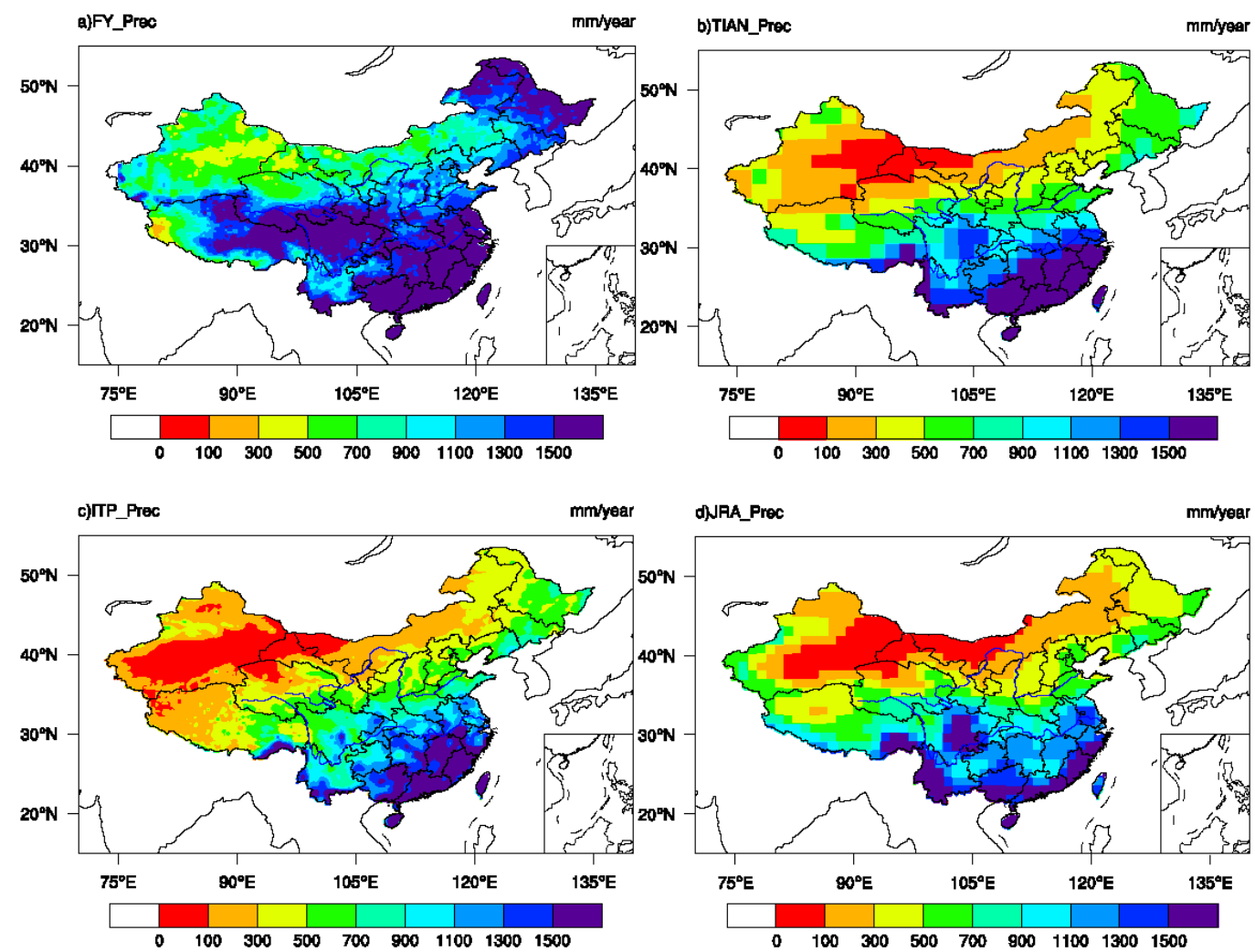

Fig. 3. Precipitation ( $\mathrm{mm} \mathrm{yr}^{-1}$ ) averaged for July 2005-June 2010 from: (a) FY; (b) TIAN; (c) ITP; (d) JRA.

The four sets of simulated soil-moisture data were then merged, using simple arithmetical averaging and BMA ensemble approaches.

\subsection{Ensemble approach}

The ensemble approaches have been found to be quite effective in improving soil moisture simulations. The simplest ensemble approach (simple arithmetical averaging) and an advanced ensemble approach (BMA) were both used in this study. Raftery et al. (2005) proposed a BMA approach which involves statistical post-processing to produce calibrated and sharply predictive PDFs from ensembles of dynamic models, and provide a reliable description of the total modeling uncertainty. The BMA predictive PDF is a weighted average of PDFs centered on the bias-corrected forecasts from a set of individual ensemble members, based on measures of their probabilities, with the better-performing ensemble members being assigned a higher weighting than those that produced less satisfactory results:

$p\left(y \mid\left(f_{1}, \cdots, f_{K}, y^{\mathrm{T}}\right)\right)=\sum_{k=1}^{K} w_{k} p_{k}\left(y \mid\left(f_{k}, y^{\mathrm{T}}\right)\right)$, where $y$ is the predictive variable, $f_{k}, k=1,2, \cdots, K$ is the $k$ th ensemble member forecasts, $K$ is the number of ensemble members being combined, $y^{\mathrm{T}}$ are the training data, $p_{k}\left(y \mid\left(f_{k}, y^{\mathrm{T}}\right)\right)$ is the conditional PDF of $y$ based on ensemble member $f_{k}$, given that $f_{k}$ is the best forecast in the ensemble. The weighting $w_{k}$ is the posterior probability of forecast, such that it is non-negative and $\sum_{k=1}^{K} w_{k}=1$, and represents the contribution of ensemble member $k$ to the predictive skill of the ensemble. From Eq. (9), we obtain the posterior predictive PDF of the predictive variable, such as soil moisture in this study. In the original BMA approach, Raftery et al. (2005) assumed that the conditional PDF was Gaussian, but the probability distribution of soil-moisture error is nonGaussian. Tian et al. (2011) found that the gamma distribution gives a better approximation of the soil-moisture error than the Gaussian distribution. In the BMA we developed and used, we assumed that the conditional PDF $p_{k}\left(y \mid\left(f_{k}, y^{\mathrm{T}}\right)\right)$ from each ensemble member at the specific time and location was approximated as a gamma distribution:

$p_{k}\left(y \mid\left(f_{k}, y^{\mathrm{T}}\right)\right)=\frac{1}{\beta_{k}^{\alpha_{k}} \Gamma\left(\alpha_{k}\right)} y^{\alpha_{k}-1} \exp \left(-y / \beta_{k}\right)$,

where $\Gamma\left(\alpha_{k}\right)$ is the gamma function. The shape parameter $\alpha_{k}$ and scale parameter $\beta_{k}$ of the gamma distribution are given by 

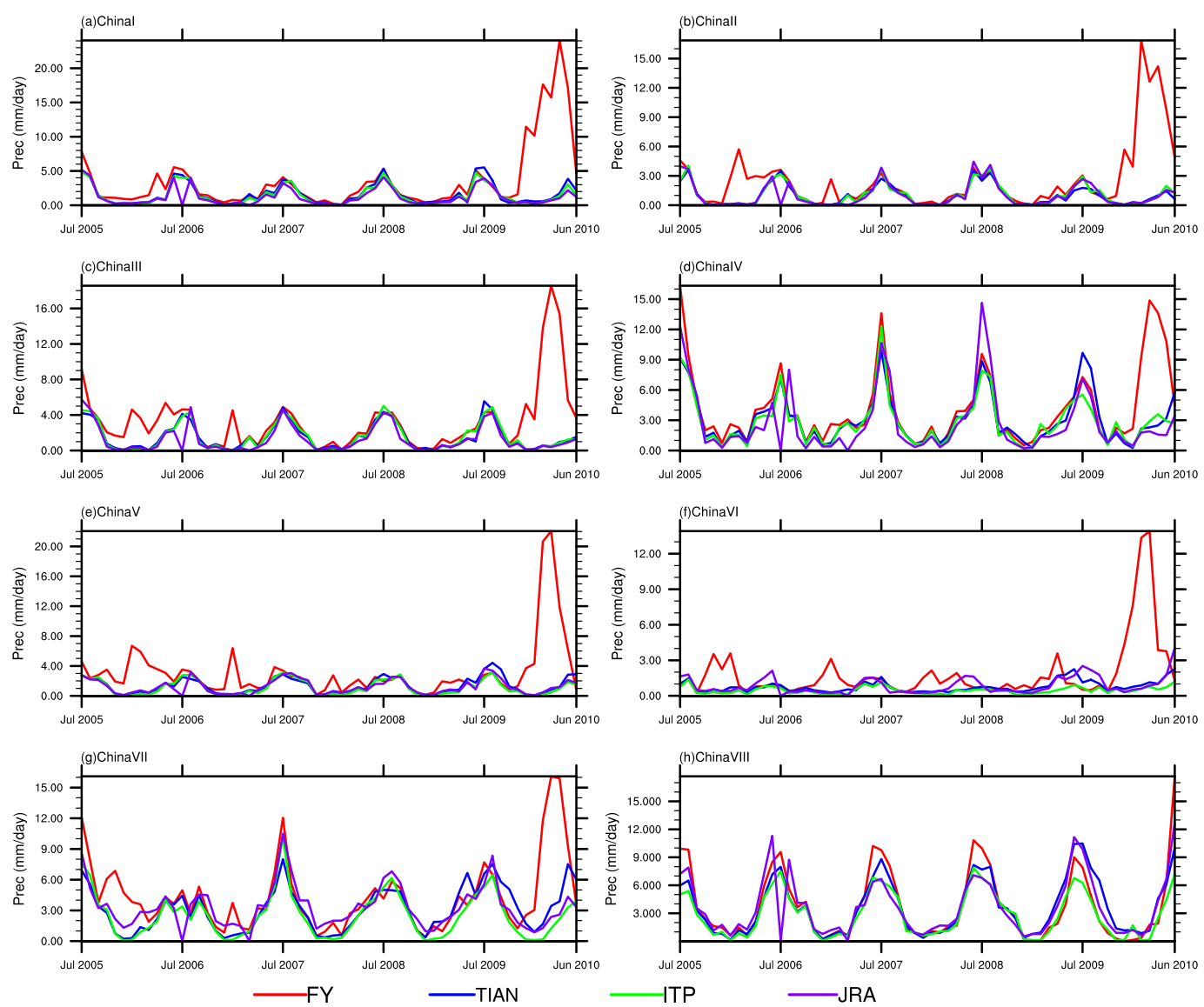

Fig. 4. Time series of precipitation (prec, $\mathrm{mm} \mathrm{day}^{-1}$ ) for July 2005-June 2010 from FY, TIAN, ITP and JRA in the eight subregions of China defined in Table 1.

$$
\begin{array}{r}
\mu_{k}=\alpha_{k} \beta_{k}=b_{0 k}+b_{1 k} f_{k}, \\
\sigma_{k}^{2}=\alpha_{k} \beta_{k}^{2}=c_{0}+c_{1} f_{k},
\end{array}
$$

where $\mu_{k}$ and $\sigma_{k}^{2}$ are the mean and variance of the gamma distribution, and $b_{0 k}, b_{1 k}, c_{0}, c_{1}$ are the parameters to be estimated. The mean of the BMA posterior PDF is the deterministic forecast. In this study, we considered only the deterministic forecast of the BMA method for the soil moisture.

The BMA parameters were estimated from a training dataset using the linear regression method and the maximum likelihood technique for which the values were obtained iteratively using the modified Markov chain Monte Carlo (MCMC) algorithm following Vrugt et al. (2008). In the present study, July 2005-June 2008 was chosen as the training period, and July 2008-June 2010 as the evaluation period. In spatial distribution, the BMA parameters were relocated from data-rich areas to data-sparse or no-data areas, based on the distribution compartmentalization of climate defined in Table 1.

\section{Results}

\subsection{Spatial distribution and temporal variation}

The soil moisture was observed only for the $0-10 \mathrm{~cm}, 10$ $20 \mathrm{~cm}$ and $70-100 \mathrm{~cm}$ soil layers; since the soil layer thicknesses in CLM3.5 did not match the thicknesses at which the in situ observations were made, the multiple soil layers in CLM3.5 were adjusted to the three observed soil layer thicknesses by the weighted averages of soil layer thicknesses.

Figure 5 shows the spatial distribution for the five-year (July 2005-June 2010) averaged volumetric soil moisture derived from CLM3.5 simulations driven by the above four forcings, their simple arithmetical averaging ensemble (referred to as CLM3.5_mean from here on), their BMA ensemble (referred to as CLM3.5_BMA from here on), and observed values in the $0-10 \mathrm{~cm}$ soil layer (the first column in Fig. 5), 10-20 cm soil layer (the second column in Fig. 5) and $70-100 \mathrm{~cm}$ (the third column in Fig. 5). For the soil moisture in the $0-10 \mathrm{~cm}$ soil layer, the observed soil moisture over mainland China (Fig. 5a, first column) displays obvious northwest-northeast and northwest-southeast gradients from dry to wet. Soil drought $\left(<0.14 \mathrm{~m}^{3} \mathrm{~m}^{-3}\right.$, Fig. 5a, first 

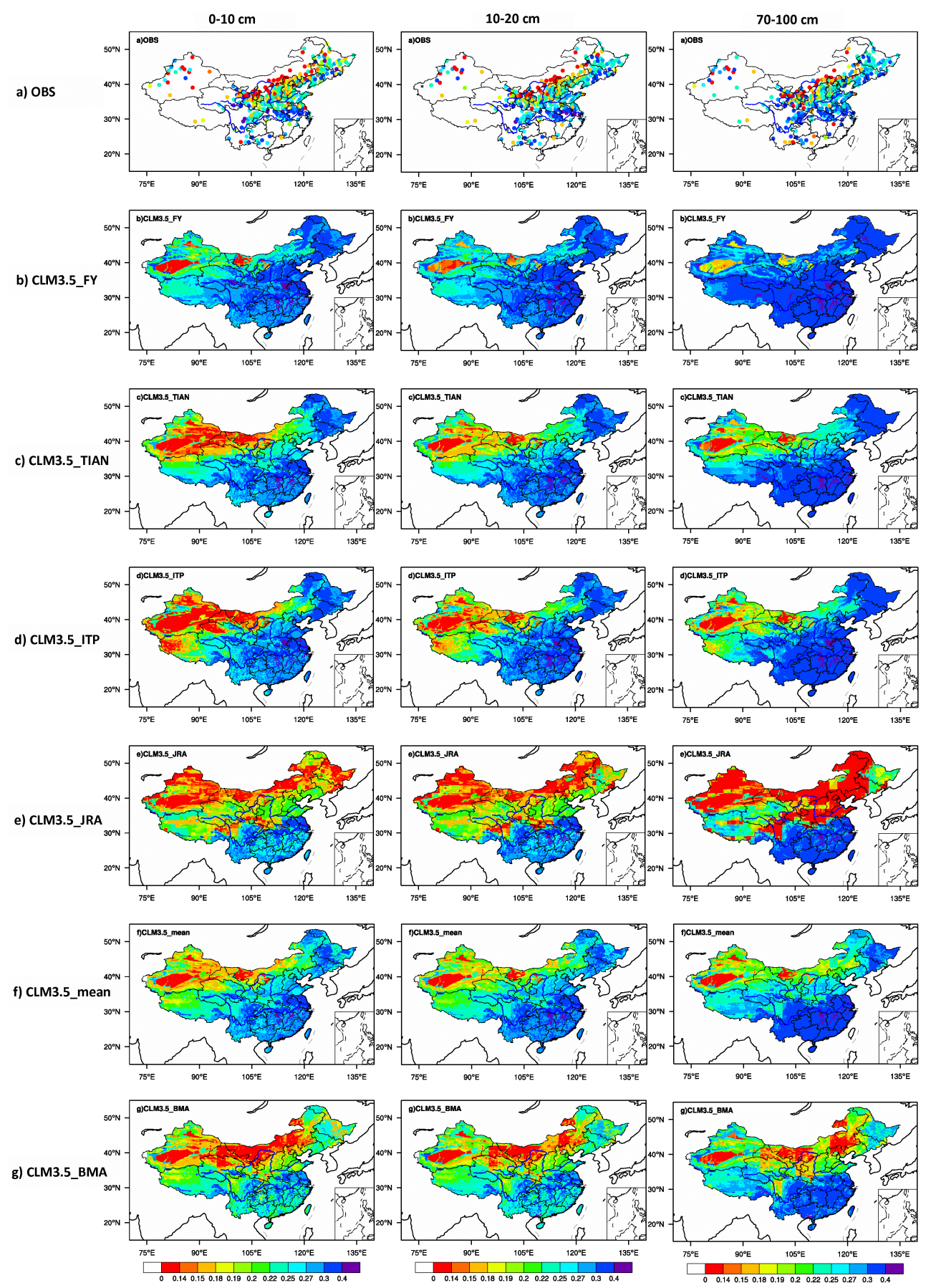

Fig. 5. Mean volumetric soil moisture $\left(\mathrm{m}^{3} \mathrm{~m}^{-3}\right)$ averaged for July $2005-J u n e ~ 2010$ in $0-10 \mathrm{~cm}$ soil layer (first column), 10-20 cm soil layer (second column), 70-100 cm soil layer (third column): (a) observations (OBS); (b) CLM3.5_FY; (c) CLM3.5_TIAN; (d) CLM3.5_ITP; (e) CLM3.5_JRA; (f) CLM3.5_mean; (g) CLM3.5_BMA.

column) is evident in most of Xinjiang, western Gansu, Inner Mongolia and the Hetao region; wetter soil appears over part of the northeast and most of southeast. The spatial pattern is generally consistent with the analysis of in situ soilmoisture observations from Sun et al. (2005). Figure 5b-e in the first column indicate that the soil moisture simulated by all four forcings generally captured the spatial pattern of soil moisture in most cases, but the CLM3.5_FY, CLM3.5_TIAN and CLM3.5_ITP simulated moisture content was wetter than observed values, especially CLM3.5_FY over the Hai River basin. CLM3.5_JRA predicted drier soil than observed over northern China, especially in the northeast. In summary, a 

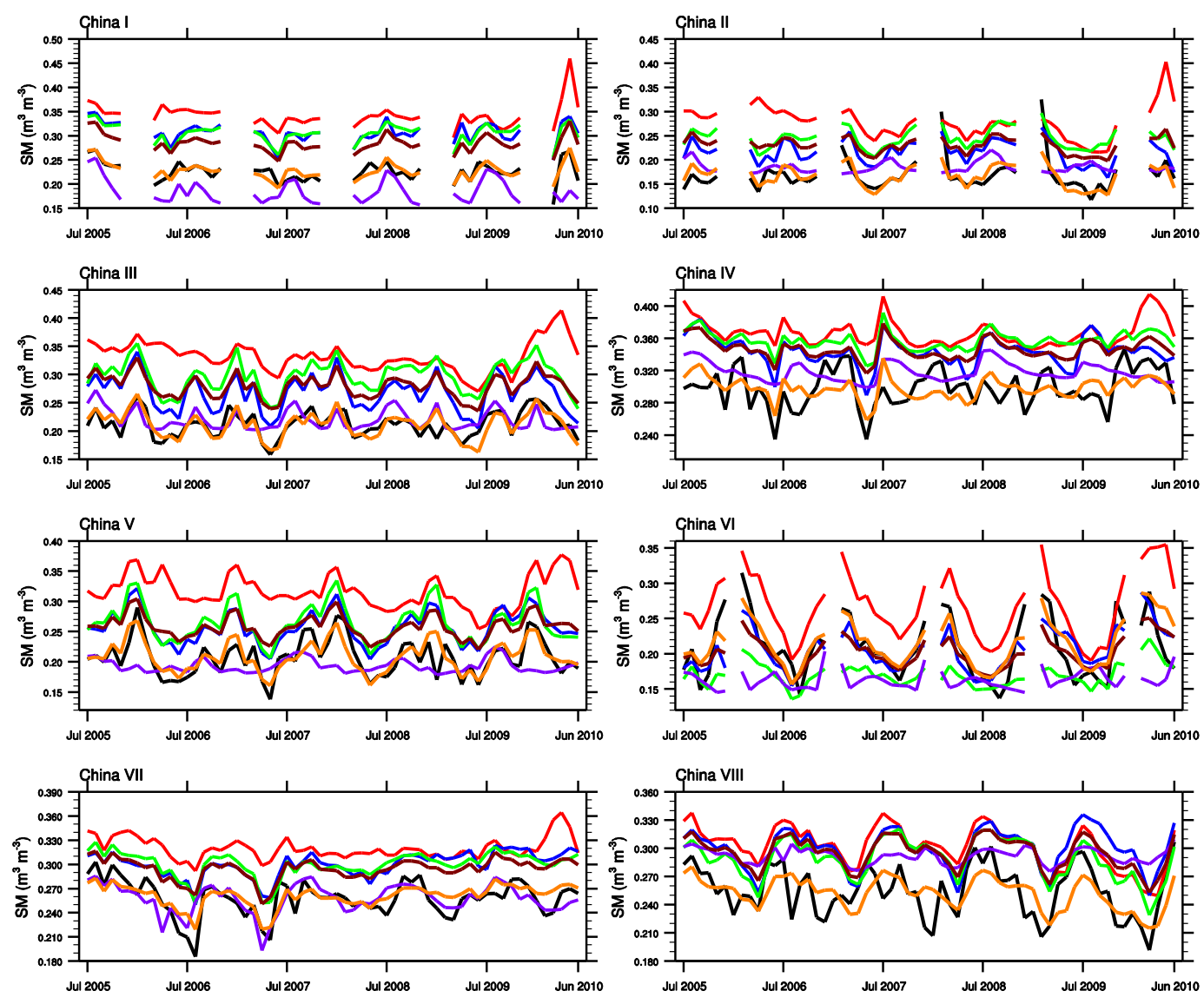

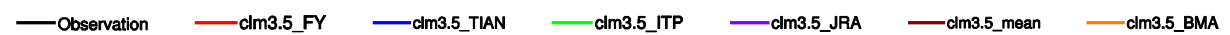

Fig. 6. Time series of monthly volumetric soil moisture $\left(\mathrm{SM}, \mathrm{m}^{3} \mathrm{~m}^{-3}\right)$ for the $0-10 \mathrm{~cm}$ soil layer from observations, CLM3.5_FY, CLM3.5_TIAN, LM3.5_ITP, CLM3.5_JRA, CLM3.5_mean and CLM3.5_BMA in the eight subregions of China defined in Table 1.

mean bias was revealed in the CLM3.5 soil-moisture simulation when individual forcings were used. Precipitation had a dominant impact on the soil-moisture variation. Comparison of the precipitations from the four forcing and four simulated soil-moisture values showed that the simulated soil moisture in Fig. 5b-e (first column) had a similar spatial pattern to that for precipitation in Fig. 3, but some differences were evident in the spatial patterns of precipitation and soil moisture. For example, the higher simulated precipitation from JRA in China VII may merely represent increased runoff and evaporation of the precipitation intercepted by the canopy without increasing soil moisture. Figure $5 \mathrm{f}-\mathrm{g}$ (first column) show that CLM3.5_mean and CLM3.5_BMA reduced the mean bias, resulting in a spatial distribution that approximated the observed values more closely than the individual members, and captured the locations of the several soil moisture drought centers very well. Also, CLM3.5_mean was wetter than the observed values; CLM3.5_BMA clearly captured several dryness and wetness centers in mainland China, and it approximated the observed values spatially.
The second and third columns repeat the maps of the first column in Fig. 5, with the 10-20 cm and 70-100 cm soil layers shown. Both the $0-10 \mathrm{~cm}$ and $10-20 \mathrm{~cm}$ soil layers are the upper soil layers, and the spatial distribution in the 10 $20 \mathrm{~cm}$ soil layer in Fig. 5 (second column) basically agrees with the first column, and the performance is similar. For the $70-100 \mathrm{~cm}$ layer (third column in Fig. 5), the spatial patterns of soil moisture for all simulations coincide with observations in most cases, but spatial distribution varies much less than the 0-10 cm layer (first column in Fig. 5), and the mean bias is much greater. Possible causes include the inability of CLM3.5 to simulate the variation of soil moisture at deeper soil layers, or alternatively the relatively short spin-up time. Figure 5g shows that CLM3.5_BMA greatly improved the simulated results, and agreed more closely with the observed spatial patterns in the $0-10,10-20$ and $70-100 \mathrm{~cm}$ soil layers.

To quantitatively examine the performance of CLM3.5 simulations of soil moisture driven by the four individual forcings and their ensemble simulations, we compared the 

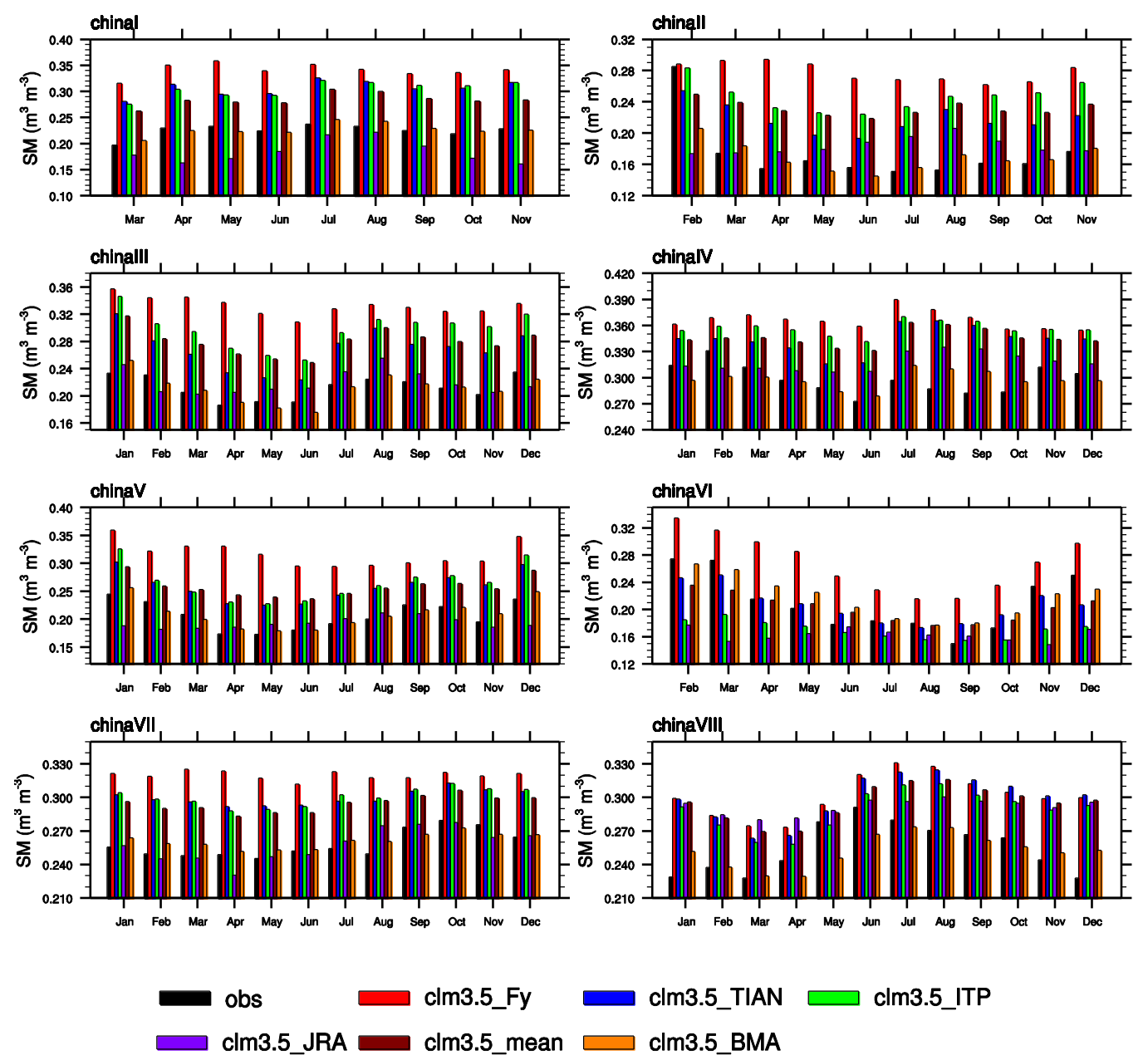

Fig. 7. July 2005-June 2010 mean monthly volumetric soil moisture $\left(\mathrm{SM}, \mathrm{m}^{3} \mathrm{~m}^{-3}\right)$ for the $0-10 \mathrm{~cm}$ soil layer from observations, CLM3.5_FY, CLM3.5_TIAN, CLM3.5_ITP, CLM3.5_JRA, CLM3.5_mean and CLM3.5_BMA in the eight subregions of China defined in Table 1.

simulated and observed monthly volumetric soil moisture time series averaged over the eight subregions defined in Table 1 . In this study, the observational stations are widely scattered, with the result that the area averages of simulated volumetric soil moisture count only those grid cells closest to the relevant observation stations.

Figure 6 shows the comparisons between simulated and observed monthly volumetric soil moisture in the 0 $10 \mathrm{~cm}$ soil layer for the period July 2005-June 2010 in the eight subregions for each of the four models, and also for CLM3.5_mean and CLM3.5_BMA. CLM3.5_FY, CLM3.5_TIAN and CLM3.5_ITP all generally captured the seasonal cycle and temporal evolution of the observed soil moisture reasonably well, but overestimated the amplitude for most subregions in mainland China, predicting much higher soil-moisture values than observed. CLM3.5_JRA performed somewhat worse in capturing the temporal evolution of soil moisture, but showed a smaller bias than the other three. For the eight subregions, the temporal variation trends and magnitudes of soil moisture shown in Fig. 6 are generally consistent with precipitation (Fig. 4). Precipitation played an important role in these soil-moisture simulations, especially in the surface layer, but this was not the only aspect to be considered. For example, CLM3.5_TIAN and CLM3.5_ITP overestimated the observed soil moisture in eastern China (China I-IV), yet slightly underestimated it in the northwest (China VI); these findings are consistent with those of Wang and Zeng (2011) and Wang et al. (2011), and may be related to deficiencies in CLM3.5, e.g., scaling of canopy interception (Lawrence et al., 2007), soil texture and model structure. The CLM3.5_mean and CLM3.5_BMA ensembles showed considerable improvement over individual forcing simulations. CLM3.5_BMA produced a closer simulation of the observed values of the temporal evolution of both soil moisture and seasonal phases, and greatly reduced 
the mean bias. It also approximated the observed time series most closely.

It should be noted that LSM simulations usually reproduce anomalies and seasonal variations but fail to simulate the mean soil moisture (Entin et al., 2000; Gao and Dirmeyer, 2006; Qian et al., 2006); the BMA approach applied in the present study did simulate the mean soil-moisture values.

For the $10-20 \mathrm{~cm}$ soil layer (figure not shown), the temporal variation basically agrees with the map in Fig. 6 and has a similar performance for the eight subregions. For the $70-100 \mathrm{~cm}$ soil layer (figure not shown), in six experiments the simulation agreed with the observed temporal variation in the China I-VII subregions, but most did not capture the observed temporal variation well in the China VIII subregion. This may be due to the dense vegetation, copious rainfall, the shortage of observations, and the complex terrain in southern China. In subregions China I and II, the temporal variation was much smaller and the mean bias was much greater than that shown in Fig. 6. CLM3.5 JRA performed worst in this soil layer, substantially underestimating the soil moisture in northern China (China I, II and V). This may be due to that the precipitation from JRA is drier than that from other three forcing and indicates a higher peak value in the wet season (Fig. 4). The higher peak value in the wet season will increase the runoff. In addition, simulation of soil moisture in deep soil layers is not only related to forcing precipitation, but also to soil processes, vegetation processes and other variables considered in CLM3.5. CLM3.5_BMA performed best of all six simulations, both for temporal variation and mean soil moisture.

Figure 7 compares the six simulations, averaged over the eight subregions, with the observed annual soil-moisture cycle in the $0-10 \mathrm{~cm}$ soil layer. All six simulations generally captured the annual cycle in most subregions, but CLM3.5_FY was too wet; CLM3.5_TIAN and CLM3.5_ITP predicted slightly wetter values than observed; CLM3.5_JRA had a smaller bias and were drier than observations in northern China, especially for the deep soil layer $(70-100 \mathrm{~cm}$, not shown in Fig. 7); CLM3.5_BMA agreed very closely with observation. For the $10-20 \mathrm{~cm}$ and $70-100 \mathrm{~cm}$ soil layers, the annual cycles were comparable (not shown in Fig. 7).

\subsection{Statistical comparison between simulation and in situ observation}

As a further quantitative illustration of the advantages of the BMA ensemble approach in improving the simulation of soil moisture, statistical scores of correlation coefficient $(R)$, mean bias error (MBE), root mean square error (RMSE) and normalized standard deviation (SDV) were used to further examine the performance of the six simulations. $R$ and SDV were plotted on two-dimensional Taylor diagrams (Taylor, 2001). The SDV is displayed as radial distance, $R$ for in situ observations as an angle in the polar plot, and the in situ observation as a point on the $x$ axis at $R=1$ and $\mathrm{SDV}=1$
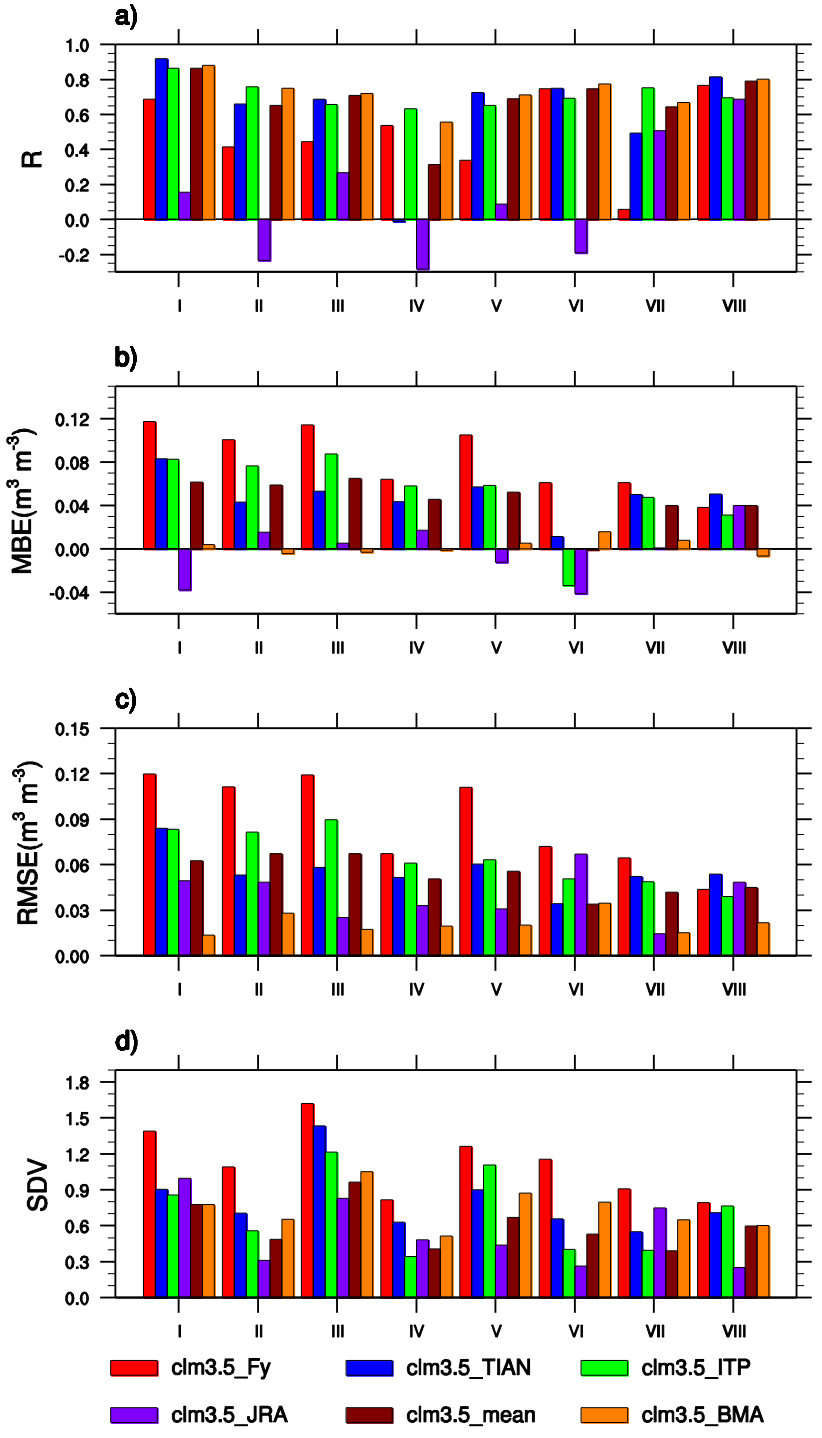

Fig. 8. Statistical scores for CLM3.5_FY, CLM3.5_TIAN, CLM3.5_ITP, CLM3.5_JRA, CLM3.5_mean and CLM3.5_BMA in the validation period July $2008-J u n e ~ 2010$ in the $0-10 \mathrm{~cm}$ soil layer in the eight subregions of China defined in Table 1: (a) correlation coefficient $(R)$; (b) mean bias error (MBE); (c) root mean square error (RMSE); (d) normalized standard deviation (SDV).

(recorded as REF). The distance between the point "REF" and the other points representing the model is the centered normalized root mean square difference between the model and in situ patterns.

The statistical post-processing in the BMA method requires training data to calibrate the BMA model parameters. We chose July 2005-June 2008 as the training period and July 2008-June 2010 as the evaluation period. The statistical scores of the six simulations in the $0-10 \mathrm{~cm}$ soil layer are presented in Fig. 8 for each of the eight subregions. For the individual forcing experiments, CLM3.5_ITP 

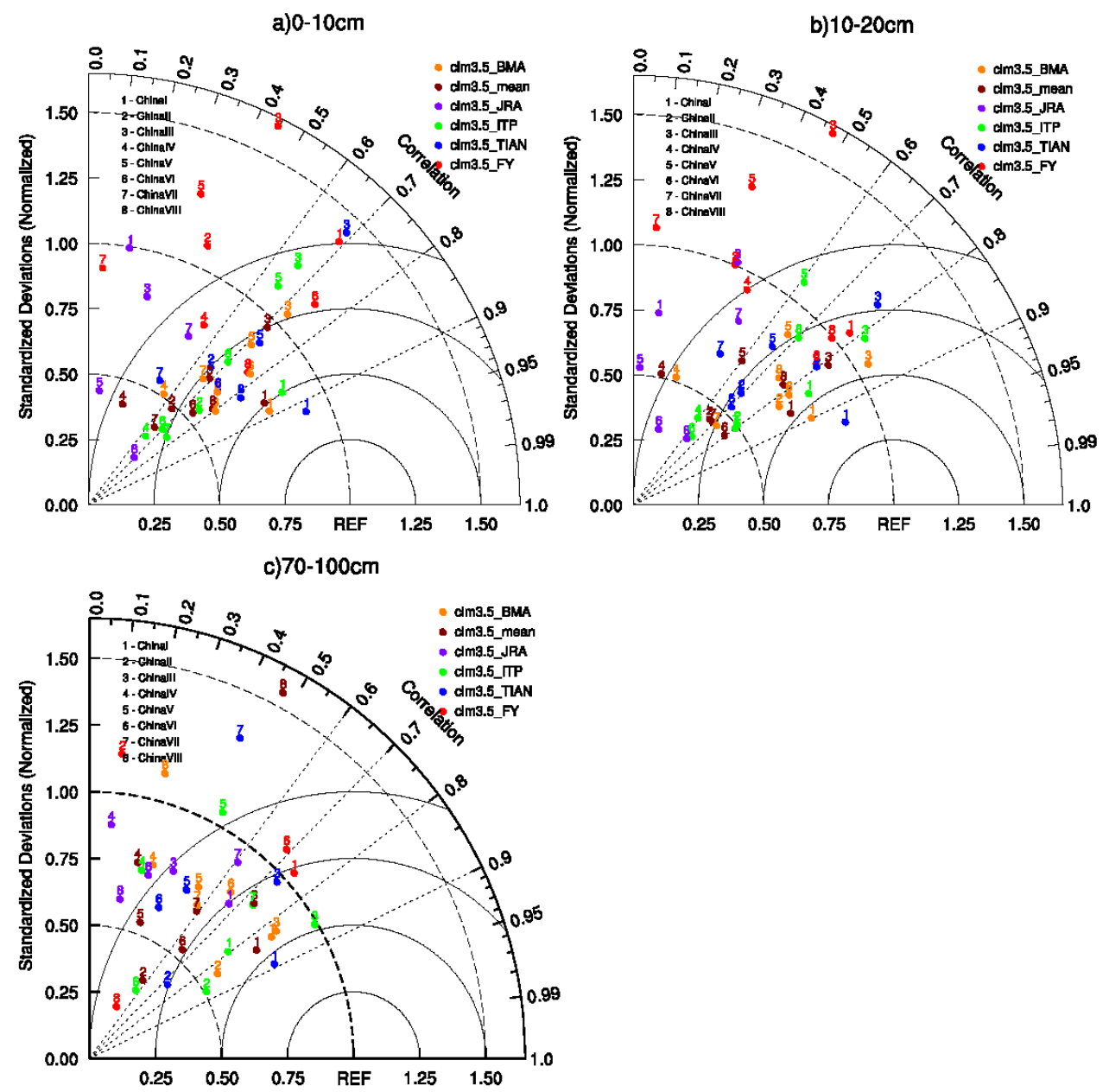

Fig. 9. Taylor diagram illustrating the comparison between CLM3.5_FY, CLM3.5_TIAN, CLM3.5_ITP, CLM3.5_JRA, CLM3.5_mean, CLM3.5_BMA and in situ observation in the eight subregions of China defined in Table 1 for the validation period July 2008-June 2010 in: (a) 0-10 cm soil layer; (b) $10-20 \mathrm{~cm}$ soil layer; (c) $70-100 \mathrm{~cm}$ soil layer.

and CLM3.5_TIAN showed good temporal correlation $(R)$ ranging from 0.5 to 0.8 in most subregions. CLM3.5_JRA performed worst in temporal correlation, and is shown to have negative correlation in Fig. 8a. Figure $8 \mathrm{~b}-\mathrm{c}$ show that CLM3.5_JRA produced a relatively small MBE and RMSE, whereas the other three individual forcing experiments each showed a relatively large MBE and RMSE. The standard deviation of CLM3.5_FY approximated in situ observations most closely (i.e., SDV approximated 1 most closely) (Fig. 8d). Figure 8 also shows that only some of the individual forcing experiments ranked highly, and this was only in some of the subregions. None of the individual forcing experiments ranked highest in all subregions.

CLM3.5_mean ranked highly over most subregions but it did not outperform all the individual members. The CLM3.5_BMA ranked highly over all subregions for all fields and performed better than CLM3.5 mean over most subregions, and performed best in temporal correlation $(R)$ over China II, III and VI subregions, in MBE over all subregions except China VI and VII, in RMSE over all subregions except China VII, and in SDV over China III and VI subregion for all fields. In general, The CLM3.5_BMA performed best for all fields over most of the subregions.

The statistical scores of six different experiments in the $10-20 \mathrm{~cm}$ and $70-100 \mathrm{~cm}$ soil layers show similar outcomes with those in the $0-10 \mathrm{~cm}$ soil layer, but the quality of the prediction deteriorated with greater soil depth; for instance, in the China IV and VIII subregions, the BMA ensemble was less dominant in temporal correlation (figure not shown).

Figure 9 shows three Taylor diagrams comparing the six experiments with observed values over the eight subregions: Fig. 9a is for the $0-10 \mathrm{~cm}$ soil layer, Fig. $9 \mathrm{~b}$ is for the $10-20 \mathrm{~cm}$ soil layer and the Fig. $9 \mathrm{c}$ is for the $70-100 \mathrm{~cm}$ soil layer. (Negative correlations are not shown in Taylor diagrams.) Figure 9 shows clearly that the CLM3.5_ITP generally performed best of the four individual forcing 


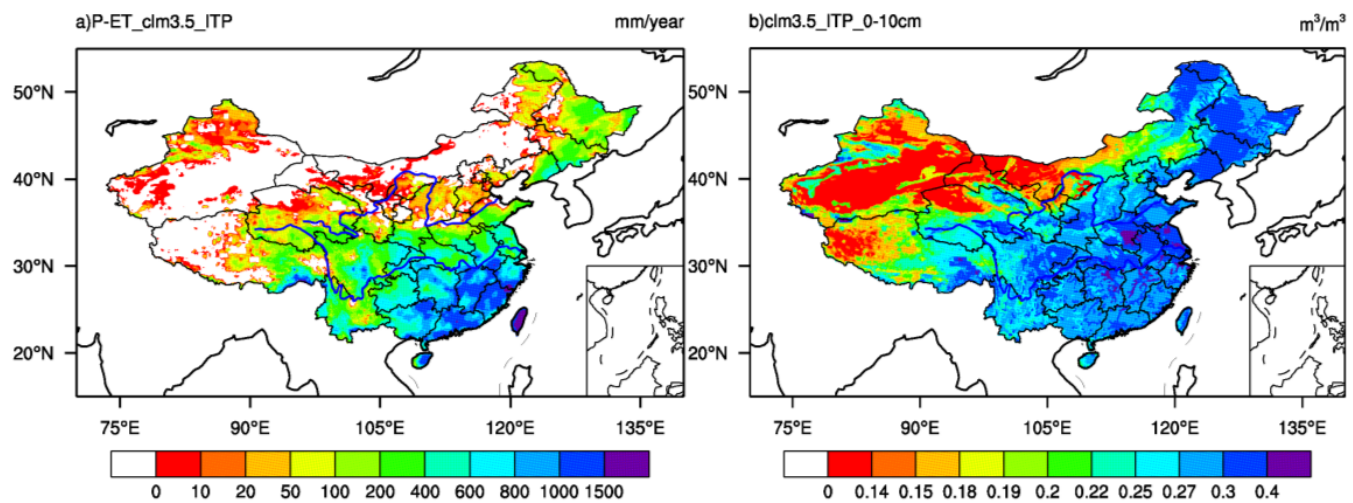

Fig. 10. Comparison between: (a) mean precipitation minus simulated evapotranspiration $(P-\mathrm{ET})$; and (b) simulated mean volumetric soil moisture in the $0-10 \mathrm{~cm}$ soil layer averaged for July 2005-June 2010 by CLM3.5 using ITP forcing.

experiments, and CLM3.5_BMA performed best of all six experiments in general, in most cases. Also, it is shown clearly that the performances of the simulations deteriorated with greater soil depth in the Fig. 9. The BMA ensemble approach improved the quality of simulated soil moisture significantly, not only in better simulation of the spatial (Fig. 5) and temporal variation (Fig. 6), but also in reducing the mean bias (Figs. 5-7).

\section{Discussion}

The uncertainty of LSM-simulated soil moisture mainly derives from the uncertainty of the meteorological forcing that is used, and also on the LSM parameterization method. This suggests that more effort is needed to reduce the uncertainty and improve the soil-moisture simulation. Due to the lack of available long-term soil-moisture data, the BMA ensemble approach was applied to multiple forcings and a multi-model ensemble for simulating soil moisture, and showed promise as a way of reproducing accurate and high-resolution longterm spatial and temporal soil-moisture data, which in turn is very important for the study of long-term hydrological variation at the land surface.

Some limitations to this study should be noted. Firstly, while we have demonstrated that the BMA method reduces the modeling uncertainty and improves modeling overall, the method depends on the accuracy of observed field values to provide an adequate training dataset for calibrating the model parameters. In this study we assumed that the local observations of the station were true values; the uncertainty of the soil-moisture observations was not discussed.

Secondly, we did not consider the uncertainty introduced by the scale mismatch between observation and simulation. The thicknesses of the observed soil layers were different from those demanded by the CLM3.5 simulation software, requiring the multiple soil layer thicknesses in CLM3.5 to be adjusted to the three observed soil layer thicknesses using the weighted averages of the thicknesses in CLM3.5. Also, since the spatial scale coverage of local station observations did not match the size of the CLM3.5 grid, it was necessary to choose a CLM3.5 grid that most closely matched the distance between local station observations. These uncertainties were not considered in this study.

Thirdly, the BMA ensemble approach depends on the availability of observational data; measured soil-moisture information in China is sparse, especially in southern China. Therefore spatial BMA parameters must be transferred from data-rich areas to data-sparse or no-data areas. In this study, we transferred parameters based on the partitioning of climate types, as set out in Table 1. However, the spatial variation of soil moisture is large (Liu et al., 2001; Minet et al., $2011)$ and it is sensitive to precipitation $(P)$, radiation and temperature; in other words, it is related to $P$ and evapotranspiration $(P-\mathrm{ET})$, but it is not merely equal to $P$-ET multiplied by a simple scale factor because it is also closely related to the soil processes, vegetation processes and other input information that can be manipulated by CLM3.5. As an example, Fig. 10 shows $P$-ET compared to simulated soil moisture, illustrating that the simulated soil moisture is the result of precipitation, temperature and radiation of forcing, together with soil, vegetation and other processes in CLM3.5 at a regional scale. Although this method of transferring BMA parameters improves the simulation in some ways, the uncertainty in the method remains to be addressed. In cases in which the observational data are sparse, other methods might be found to be appropriate: for example, a comprehensive parameter-transfer approach that embraces climate, hydrology, vegetation and soil texture properties may improve simulated soil-moisture patterns.

\section{Summary and conclusion}

This study investigated the extent to which the quality of soil-moisture simulation is improved by using a multiple 
meteorological forcings ensemble approach. Four meteorological forcings developed by different institutions were used in the LSM numerical model CLM3.5 to simulate the moisture content of soils across mainland China. All simulations were performed on a grid at $0.1^{\circ}$ resolution. Two ensemble approaches (simple arithmetical averaging, and BMA) were then applied to the resulting four sets of simulations. The simulated soil moisture from all six experiments were then compared to in situ measured soil moisture from 411 stations in eight subregions across mainland China for the period July 2005-June 2010. The major conclusions are stated in the following paragraphs.

The CLM3.5 simulations of soil moisture using the four individual forcings generally captured the spatial pattern and seasonal variation of soil moisture in these areas, but produced some mean bias when compared with the observed in situ soil-moisture values. Of the four individual forcing experiments, CLM3.5_ITP and CLM3.5_TIAN showed the best correlation, CLM3.5_JRA had the lowest mean bias, and the variation of soil-moisture values produced by CLM3.5_FY was generally consistent with measured values. In general, CLM3.5_ITP performed best and CLM3.5_JRA performed worst in most subregions. This result is associated with the quality of the meteorological forcing: for example, ITP, TIAN and FY require substantial numbers of measured values to be merged with remote sensing observations.

The performances of the simulations in the top soil layers $(0-10 \mathrm{~cm}$ and $10-20 \mathrm{~cm})$ were superior to those at $70-$ $100 \mathrm{~cm}$, which is associated with the ability of CLM3.5 to simulate soil moisture in the deeper soil layers, and the mismatch between the actual measured soil layer depths and the theoretical depths that are part of the design of the CLM3.5 model. The simulated soil-moisture values in northern China were found to approximate more closely to in situ observed values than those in southern China (subregions China IV, VII and VIII). This result was presumably related to the copious rainfall in those subregions together with the scarcity of observational data, the dense vegetation, the complex terrain and the soil texture.

Ensembles based on combining the four meteorological forcings improved the accuracy of the simulated soil moisture. The simple arithmetical averaging ensemble ranked highly in most subregions, but did not produce the best of the results in all categories in most subregions. The BMA ensemble performed better, being best over most of the subregions in general. The BMA ensemble approach significantly improved the ability to accurately simulate soil moisture. It is a promising way of reproducing the mean value and variation in volumetric soil moisture.

Acknowledgements. This research was supported by the National Natural Science Foundation of China (Grant Nos. 91125116 and 41075062), the National Basic Research Program of China (Grants Nos. 2010CB951101 and 2010CB428403), and the Special Funds for Public Welfare of China (Grant No. GYHY201006037). The authors gratefully acknowledge Chunxiang Shi at the China Meteorological Administration (CMA) for providing in situ observations of soil moisture and the FY meteorological forcing data; Jie $\mathrm{He}$ for providing the ITPCAS meteorological forcing data; Xiangjun Tian for providing the TIAN meteorological forcing data; and JMA for providing the JRA meteorological forcing data. We also thank Marnik Vanclooster for his valuable comments and suggestions.

Edited by: M. Vanclooster

\section{References}

Albergel, C., de Rosnay, P., Balsamo, G., Isaksen, L., and MuñozSabater, J.: Soil moisture analyses at ECMWF: Evaluation using global ground-based in situ observations, J. Hydrometeor., 13, 1442-1460, 2012.

Chen, Y., Yang, K., He, J., Qin, J., Shi, J., Du, J., and He, Q.: Improving land surface temperature modeling for dryland of China, J. Geophys. Res., 116, D20104, doi:10.1029/2011JD015921, 2011.

Duan, Q. Y., Ajami, N. K., Gao, X. G., and Sorooshian, S.: Multimodel ensemble hydrologic prediction using Bayesian model averaging, Adv. Water Res., 30, 1371-1386, 2007.

Entin, J. K., Robock, A., Vinnikov, K. Y., Hollinger, S., Liu, E. S., and Namkhai, A.: Temporal and spatial scales of observed soil moisture variations in the extratropics, J. Geophys. Res., 105, 11865-11877, 2000.

Gao, X. and Dirmeyer, P. A.: A multimodel analysis, validation and transferability study of global soil wetness products, J. Hydrometeor., 7, 1218-1236, 2006.

Guo, Z. C., Dirmeyer, P. A., Gao, X., and Zhao, M.: Improving the quality of simulated soil moisture with a multi-model ensemble approach, Q. J. Roy. Meteorol. Soc., 133, 731-747, 2007.

He, J.: Development of surface meteorological dataset of China with high temporal and spatial resolution, M.S. thesis, Inst. of Tibetan Plateau Res., Chin. Acad. of Sci., Beijing, China, 2010.

Huffman, G. J., Adler, R. F., Bolvin, D. T., Gu, G., Nelkin, E. J., Bowman, K. P., Hong, Y., Stocker, E. F., and Wolff, D. B.: The TRMM multi-satellite precipitation analysis (TMPA): Quasiglobal, multi-year, combined-sensor precipitation estimates at fine scales, J. Hydrometeorol., 8, 38-55, 2007.

Jia, B., Tian, X., Xie, Z., Liu, J., and Shi, C.: Assimilation of microwave brightness temperature in a land data assimilation system with multi-observation operators, J. Geophys. Res. Atmos., 118, 3972-3985, doi:10.1002/jgrd.50377, 2013.

Lawrence, D. M., Thornton, P. E., Oleson, K. W., and Bonan, G. B.: The partitioning of evapo-transpiration into transpiration, soil evaporation, and canopy evaporation in a GCM: Impacts on landatmosphere interaction, J. Hydrometrorol., 8, 862-880, 2007.

Lawrence, P. J. and Chase, T. N.: Representing a new MODIS consistent land surface in the Community Land Model (CLM 3.0), J. Geophys. Res., 112, G01023, doi:10.1029/2006JG000168, 2007.

Li, H. B., Robock, A., Liu, S. X., Mo, X. G., and Viterbo, P.: Evaluation of reanalysis soil moisture simulations using updated Chinese soil moisture observations, J. Hydrometeorol., 6, 180-193, 2004.

Li, M. X. and Ma, Z. G.: Comparisons of simulations of soil moisture variations in the Yellow River Basin driven by various at- 
mospheric forcing data sets, Adv. Atmos. Sci., 27, 1289-1302, doi:10.1007/s00376-010-9155-7, 2010.

Liu, J. G., Xie, Z. H., Zhao, L. N., and Jia, B. H.: BMA probabilistic forecasting for the 24-h TIGGE multi-model ensemble forecasts of surface air temperature, Chinese J. Atmos. Sci., 37, 43-53, 2013 (in Chinese).

Liu, S., Mo, X., Li, H., Peng, G., and Robock, A.: Spatial variation of soil moisture in China: Geostatistical characterization, J. Meteorol. Soc. Japan, 79, 555-574, 2001.

Minet, J., Laloy, E., Lambot, S., and Vanclooster, M.: Effect of highresolution spatial soil moisture variability on simulated runoff response using a distributed hydrologic model, Hydrol. Earth Syst. Sci., 15, 1323-1338, doi:10.5194/hess-15-1323-2011, 2011.

Oleson, K. W., Lawrence, D. M., Bonan, G. B., Flanner, M. G., Kluzek, E., Lawrence, P. J., Levis, S., Swenson, S. C., Thornton, P. E., Dai, A., Decker, M., Dickinson, R., Feddema, J., Heald, C. L., Hoffman, F., Lamarque, J.-F., Mahowald, N., Niu, G.Y., Qian, T., Randerson, J., Running, S., Sakaguchi, K., Slater, A., Stockli, R., Wang, A., Yang, Z.-L., and Zeng, X.: Technical description of the community land model (CLM), Tech. Note NCAR/TN461+STR, 174 pp., Natl. Cent. Atmos. Res., Boulder $\mathrm{CO}, 2004$.

Oleson, K. W., Niu, G.-Y., Yang, Z.-L., Lawrence, D. M., Thornton, P. E., Lawrence, P. J., Stockli, R., Dickinson, R. E., Bonan, G. B., and Levis, S.: CLM 3.5 documentation, 34 pp., available at: http://www.cgd.ucar.edu/tss/clm/distribution/clm3. 5/CLM3_5_documentation.pdf (last access: 15 March 2013), 2007.

Oleson, K. W., Niu, G.-Y., Yang, Z.-L., Lawrence, D. M., Thornton, P. E., Lawrence, P. J., Stockli, R., Dickinson, R. E., Bonan, G. B., Levis, S., Dai, A., and Qian, T.: Improvements to the Community Land Model and their impact on the hydrological cycle, J. Geophys. Res., 113, G01021, doi:10.1029/2007JG000563, 2008.

Onogi, K., Tsutsui, J., Koide, H., Sakamoto, M., Kobayashi, S., Hatsushika, H., Matsumoto, T., Yamazaki, N., Kamahori, H., Takahashi, K., Kadokura, S., Wada, K., Kato, K., Oyama, R., Ose, T., Mannoji, N., and Taira, R.: The JRA-25 reanalysis, J. Meteorol. Soc. Japan, 85, 369-432, 2008.

Pinker, R. T. and Laszlo, I.: Modeling surface solar irradiance for satellite applications on a global scale, J. Appl. Meteorol., 31, 194-211, doi:10.1175/15200450(1992)031<0194:MSSIFS > 2.0.CO;2, 1992.

Qian, T., Dai, A., Trenberth, K. E., and Oleson, K. W.: Simulation of global land surface conditions from 1948 to 2004: Part I: Forcing data and evaluations, J. Hydrometeorol., 7, 953-975, 2006.

Raftery, A. E., Gneiting, T., Balabdaoui, F., and Polakowski, M.: Using Bayesian model averaging to calibrate forecast ensembles, Mon. Weather Rev., 133, 1155-1174, doi:10.1175/MWR2906.1, 2005

Robock, A., Schlosser, C. A., Vinnikov, K. Y., Speranskaya, N. A., Entin, J. K., and Qiu, S.: Evaluation of the AMIP soil moisture simulations, Global Planet. Change, 19, 181-208, 1998.

Sheffield, J., Goteti, G., and Wood, E. F.: Development of a 50-year high-resolution global dataset of meteorological forcings for land surface modeling, J. Climate, 19, 3088-3111, doi:10.1175/JCLI3790.1, 2006.
Shi, C. X.: A study on soil moisture remote sensing data assimilation based on 436 ensemble Kalman filter (EnKF), Ph.D. thesis, Institute of Atmospheric 437 Physics, Chinese Academy of Sciences, Beijing, 177 pp., 2008 (in Chinese).

Shi, C. X., Xie, Z. H., Qian, H., Liang, M. L., and Yang, X. C.: China land soil moisture EnKF data assimilation based on satellite remote sensing data, Sci. China Earth Sci., 54, 1430-1440, doi:10.1007/s11430-010-4160-3, 2011.

Sun, C. H., Li, W. J., Zhang, Z. Q., and He, J. H.: Distribution and variation features of soil humidity anomaly in Huaihe River Basin and its relationship with climatic anomaly, Q. J. Appl. Meteorol., 16, 129-138, 2005 (in Chinese).

Taylor, K. E.: Summarizing multiple aspects of model performance in a single diagram, J. Geophys. Res., 106, 7183-7192, 2001.

Tian, X., Xie, Z., Dai, A., Jia, B., and Shi, C.: A microwave land data assimilation system: Scheme and preliminary evaluation over China, J. Geophys. Res., 115, D21113, doi:10.1029/2010JD014370, 2010.

Tian, X., Xie, Z., Wang, A., and Yang, X.: A new approach for Bayesian model averaging. Sci. China Earth Sci., doi:10.1007/s11430-011-4307-x, 2011.

Vrugt, J. A., Diks, C. G. H., and Clark, M. P.: Ensemble Bayesian model averaging using Markov chain Monte Carlo sampling, Environ. Fluid Mech., 8, 579-595, 2008.

Wang, A. and Zeng, X.: Sensitivities of terrestrial water cycle simulations to the variations of precipitation and air temperature in China, J. Geophys. Res., 116, D02107, doi:10.1029/2010JD014659, 2011.

Wang, A., Bohn, T. J., Mahanama, S. P., Koster, R. D., and Lettenmaier, D. P.: Multimodel ensemble reconstruction of drought over the continental United States, J. Climate, 22, 2694-2712, 2009.

Wang, A., Lettenmaier, D. P., and Sheffield, J.: Soil moisture drought in China, 1950-2006. J. Climate, 24, 3257-3271, 2011.

Wei, J., Dirmeyer, P. A., and Guo, Z.: Sensitivities of soil wetness simulation to uncertainties in precipitation and radiation, Geophys. Res. Lett., 35, L15703, doi:10.1029/2008GL034494, 2008.

Yang, K., Koike, T., and Ye, B.: Improving estimation of hourly, daily, and monthly downward shortwave radiation by importing global datasets, Agr. Forest Meteorol., 137, 43-55, 2006.

Yatagai, A., Arakawa, O., Kamiguchi, K., Kawamoto, H., Nodzu, M. I., and Hamada, A.: A 44-year daily gridded precipitation dataset for Asia based on a dense network of rain gauges, Sci. Online Lett. Atmos. (SOLA), 5, 137-140, 2009.

Zhang, X.: Analysis and assessment of soil moisture in China based on the in situ observation data, M.S. dissertation, China Univ. of Geosci., Beijing, 2009 (in Chinese with English abstract).

Zhu, Y. F.: The regional division of dryness/wetness over Eastern China and variations of dryness/wetness in Northern China during the last 530 years, Acta Geogr. Sin., 58, Supplement, 100107, 2003 (in Chinese). 